\title{
A SIMPLE WATER QUALITY MODEL AS A TOOL FOR THE EVALUATION OF ALTERNATIVE RIVER BASIN MANAGEMENT PLANS
}

\author{
NOUTSOPOULOS C. \\ KYPRIANOU I.
}

\author{
National Technical University of Athens \\ Faculty of Civil Engineering, Department of Water Resources \\ and Environmental Engineering \\ 5, Iroon Polytechniou, Zografou, Athens 15780, Greece
}

Received: $14 / 05 / 2013$

Accepted: 16/05/2013 *to whom all correspondence should be addressed: e-mail: cnoutso@central.ntua.gr

\begin{abstract}
A key component in the implementation of Water Framework Directive is the development of a river basin management plan for each river basin district. Water quality models are important tools to test the effectiveness of alternative management plans on the water quality of the respective water bodies. The main objective of the present study was to develop and demonstrate the use of a rather simple water quality model as a tool for the evaluation of alternative water management scenarios for the river basin district of Evrotas. Furthermore an extension of the water quality model based on Monte Carlo simulation to provide for uncertainty identification is also exhibited. The model is based on the basic principles of the Streeter-Phelps model. A hierarchical approach was developed in order to delineate a complex hydrographic network into a series of water bodies being connected by convective terms. The pollution loads which were used as input data were related both to point sources and non-point sources. Based on the results a substantial removal of organic carbon load originating from the industrial activities is needed in order to achieve high dissolved oxygen concentrations throughout the entire hydrosystem even at the dry period.
\end{abstract}

KEYWORDS: Deoxygenation, Evrotas River, Monte Carlo simulation, River Basin Management Plants, Streeter-Phelps, Water Framework Directive, Water Quality Models.

\section{INTRODUCTION}

Water Framework Directive (WFD) is a European initiative which establishes a framework for the protection of inland surface waters (rivers and lakes), transitional waters, coastal waters and groundwater. A key component in the implementation of WFD is the development of a river basin management plan (RBMP) for each river basin district which will be reviewed every six years. The RBMPs must include, between others, a programme of measures by taking into account the results of the pressures and impact analysis in order to achieve the objectives of the directive.

Water quality models are important tools to test the effectiveness of alternative management plans on the water quality of the respective water bodies. Many river water quality models are practically based on the simple Streeter - Phelps model. It is well known that steady state water quality models are simpler than dynamic models and require less input data. More complex water quality models (1$D, 2-D$, or even 3-D) have also been developed and extensively been applied to evaluate the response of a river water quality to several management scenarios. Many of these water quality models are basically extensions of the simple BOD-DO model (e.g. QUAL2K) whereas there are other more detailed analytical ecological models (e.g. MIKE-11-ECOLAB, WASP, DELFT 3D WAQ, SOBEK River, IWA River Water Quality Model 1).

During the last decades the trend was on developing more detailed water quality models (Thomann 1998; Shanahan et al., 2001; Parker et al., 2007). However the increased models' complexity was not always associated with high precision of models' results (Young et al., 1996). Therefore the greatest challenge is to balance between models' complexity and results reliability. 
In any case during the evaluation of alternative water resources management scenarios for the selection of the most appropriate one, the uncertainty of models' results must be taken into account and properly identified (Beck, 1987).

Although many detailed water quality models are well referenced in a great number of case studies (Ambrose et al., 1993; Chapra and Runkel, 1998; DHI, 2000; Tsakiris and Alexakis, 2012), their applicability is limited when they are used as tools to evaluate water resources management plans undertaken on a large scale (following WFD implementation) due to the high load of input data required and the lack of uncertainty assessment of their results due to their high complexity.

Many of the input data used in water quality models such as the pollution loads, temperature, etc., exhibit a stochastic character and are governed by laws which can not be precisely quantified. Furthermore there is a high level of uncertainty when determining the appropriate values of the constants employed in the model's kinetic equations. Most of these values are derived through experimental procedures conducted under different conditions and the range between the values of each parameter that independent researchers suggest is often wide.

Monte Carlo is a well known procedure where several random sets of input data selected from known probability distributions are used to produce the probability distributions of models' results, thus providing the means to determine uncertainty of the results.

In view of the above the objectives of this study were: a) to develop a simple river water quality model and to demonstrate its use as a tool for the evaluation of alternative water management scenarios and b) to incorporate Monte Carlo simulation in the water quality model in order to provide the means for uncertainty identification.

\section{MODEL DESCRIPTION}

The mathematical model is based on the basic principles of the Streeter-Phelps model, i.e. steady state, one dimension flow, negligible diffuse phenomena and involves the parameters of organic carbon (BOD), ammonium nitrogen ( $\mathrm{NH}$ ) and dissolved oxygen (DO).

The mass balance equation for a one dimensional model can be written as follows:

$$
\frac{\partial \mathrm{C}}{\partial \mathrm{t}}+\mathrm{V}_{\mathrm{x}} \frac{\partial \mathrm{C}}{\partial \mathrm{x}}=\mathrm{E}_{\mathrm{x}} \frac{\partial^{2} \mathrm{C}}{\partial \mathrm{x}^{2}}+\mathrm{r}(\mathrm{C})
$$

where $C$ is the concentration of a pollutant, $V_{x}$ is stream's flow velocity in $x$-direction, $E_{x}$ is the dispersion coefficient in $\mathrm{x}$-direction and $\mathrm{r}(\mathrm{C})$ is the term reaction for pollutant $\mathrm{C}$.

Under steady state conditions, by neglecting the dispersion term and by considering the degradation of organic carbon, ammoniacal nitrogen oxidation (nitrification), depletion of dissolved oxygen due to heterotrophic and autotrophic bacteria respiration and supply of dissolved oxygen through physical reaeration as the only processes, the following set of equations can be derived:

$$
\begin{aligned}
& D_{x}=D_{o}+\operatorname{CBOD}_{0}\left\{\frac{K_{d}}{K_{a}-K_{d}}\left(e^{-K_{d} \frac{x}{v_{x}}}-e^{-K_{a} \frac{x}{v_{x}}}\right)\right\}+N B O D_{o}\left\{\frac{K_{N}}{K_{a}-K_{N}}\left(e^{-K_{N} \frac{x}{v_{x}}}-e^{-K_{a} \frac{x}{v_{x}}}\right)\right\} \\
& \mathrm{CBOD}_{\mathrm{x}}=\mathrm{CBOD}_{\mathrm{o}} \mathrm{e}^{-\mathrm{K}_{\mathrm{d}} \frac{\mathrm{x}}{\mathrm{v}_{\mathrm{x}}}} \\
& \mathrm{NBOD}_{\mathrm{x}}=\mathrm{NBOD}_{0} \mathrm{e}^{-\mathrm{K}_{\mathrm{N}} \frac{\mathrm{x}}{\mathrm{v}_{\mathrm{x}}}}
\end{aligned}
$$

where $D_{x}$ is the dissolved oxygen deficit at location $x\left(\mathrm{mg} \mathrm{l}^{-1}\right), D_{0}$ is the dissolved oxygen deficit $\left(\mathrm{mg} \mathrm{l}^{-1}\right)$ at $\mathrm{x}=0, \mathrm{CBOD}_{\circ}$ and $\mathrm{NBOD}_{0}$ are the concentrations of biological oxygen demand and the nitrogenous biological oxygen demand $\left(\mathrm{mg} \mathrm{l}^{-1}\right)$ respectively at $\mathrm{x}=0, \mathrm{CBOD}_{\mathrm{x}}$ and $\mathrm{NBOD}_{\mathrm{x}}$ are the concentrations at location $x$ of biological oxygen demand and the nitrogenous biological oxygen demand $\left(\mathrm{mg} \mathrm{l}^{-1}\right)$ respectively, $\mathrm{K}_{d}$ is the deoxygenation rate coefficient $\left(\mathrm{d}^{-1}\right), \mathrm{K}_{\mathrm{a}}$ is the reaeration rate coefficient $\left(d^{-1}\right)$ and $K_{N}$ is the nitrification rate coefficient $\left(d^{-1}\right)$. 
The dissolved oxygen concentration at the location $\mathrm{x}$ is calculated according to the following equation: $C_{x}=C_{s}-D_{x}$, where $C_{s}$ is the saturation concentration of dissolved oxygen. The saturation dissolved oxygen concentration depends on water temperature and salinity. By considering the low salinity content of most rivers only the influence of temperature is taking into account in the model by the following equation:

$$
C_{s}=14.652-0.41022 T+0.007991 T^{2}-0.0000777 T^{3}
$$

A hierarchical approach was developed in order to delineate a complex hydrographic network into a series of water bodies being connected by convective terms. At the beginning of each water body, point sources of BOD, dissolved oxygen and ammoniacal nitrogen can be added. Initial concentration of every parameter is calculated using the dilution equation. Furthermore in order to add the non point sources loads each water body is further divided in a number of stretches. At the beginning of each stretch the pollutional load of non point sources is added. It should be mentioned that the load of non point sources attributed at each stretch is calculated by the total load of non point sources of the water body divided by the number of stretches. The total number of stretches for each water body is calculated according to the following criterion: $\frac{L}{n} \leq 1000$, where $L$ is the total length of each water body and $n$ is the number of stretches in each water body. Therefore the mathematical model calculates the concentration of BOD, dissolved oxygen, ammoniacal nitrogen for each stretch by using the equations (1)-(5).

An extended version of the mathematical model was also developed in order to account for model's uncertainty. The extended mathematical model uses the equations already presented, whereas the Monte Carlo technique is used for the selection of the values of the constants and the input loads. The model creates a range of possible values for each of them and a corresponding probability distribution. Therefore the model selects, with a pseudo-random way, the value of each parameter through the specific probability distribution which can be normal, lognormal, uniform or triangular. Furthermore the model is taking into account any possible intecorrelation between constants (i.e. $\mathrm{K}_{d}$ and $\mathrm{K}_{\mathrm{a}}, \mathrm{K}_{\mathrm{d}}$ and $\mathrm{K}_{\mathrm{N}}$, etc.). For each application of the extended model a minimum of a thousand sets of parameters and input data were generated.

\section{CASE STUDY - DATA USED}

The mathematical model was applied for the case of Evrotas river basin district (RBD). Evrotas RBD is located in the Water District of East Peloponnese (WD03) which covers the southeast part of Peloponnese. In the Evrotas RBD with a total surface area of 2,239 $\mathrm{km}^{2}, 52$ surface water bodies and 12 groundwater bodies have been identified. From the 52 surface water bodies 49 are river water bodies, 1 is a transitional water body and 2 are coastal water bodies (Figure 1). Evrotas river basin covers most of the RBD with 44 surface water bodies classified in five river types and a total surface area of $1,680 \mathrm{~km}^{2}$. Based on the analysis of pressures performed (Ministry of Environment, Energy \& Climate Change - Special Secretariat for Water, 2013) it was evidenced that intensive livestock breading, industrial activities and agriculture significantly contributes to the pollution of the area, with respect to nutrients and oxygen limiting compounds. Urban wastewater treatment facilities do not serve all areas and therefore there are areas where septic tanks are employed, which occasionally have an impact on the nearby water bodies. As it is presented in Figure 2, industrial activities represent the $60 \%$ and $8.5 \%$ of the annual organic carbon and nitrogen load generated in the Evrotas RBD respectively.

The vast majority of the industrial activities are small scale units whereas only $29 \%$ are significant industrial units. From the moderate - large industrial units $49 \%$ are olive mill units, $21 \%$ are dairy production units, $9 \%$ are meat processing units and $9 \%$ are fruit production units. Based on the findings of the analysis of pressures the annual organic carbon load was assigned from each subcatchment (corresponding to each water body) to the stretches of the river, included in the simulation. Furthermore the load of ammoniacal nitrogen which was assigned to each stretch of the model was determined as a percentage of the total nitrogen load (estimated by the analysis of pressures) by considering that almost $80-100 \%$ of the total nitrogen in the industrial effluent, landfill liquors, fish farming, livestock and septage and the $10-20 \%$ of the total nitrogen in wastewater treatment plants effluents, cultivated and non-cultivated land runoffs are in the form of TKN (and eventually $\mathrm{NH}_{4}-\mathrm{N}$ ). The water flow rates used in the model for each month at each river stretch were 
also derived from the Evrotas river basin management plan (Ministry of Environment, Energy \& Climate Change - Special Secretariat for Water, 2013). The monthly distribution of average flow rates was estimated according to the monthly distribution of precipitation.

\section{RESULTS AND DISCUSSION}

\subsection{Application of the simple water quality model}

As already discussed the mathematical model was applied for the Evrotas RBD. The main objective of this study was to exhibit the merits from the application of simple mathematical models to the evaluation of different water resources management scenarios.

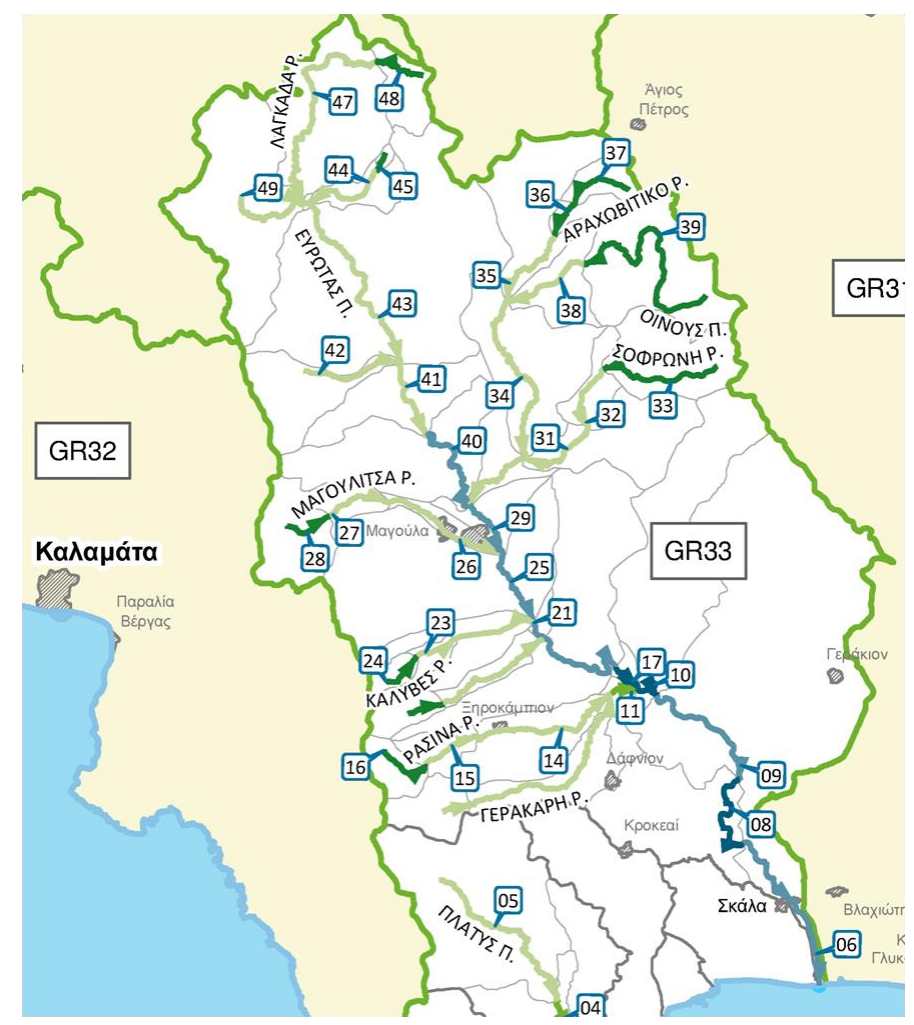

Figure 1. Water bodies in the Evrotas RBD (Ministry of Environment, Energy \& Climate Change Special Secretariat for Water, 2013)

Validation of the model using available field measurements (Life Environment, 2009) indicates a satisfactory agreement of the measured and the calculated values. More specifically the results from the application of the model for three periods (March, May and September) were evaluated against filed measurements at several locations in the river. Based on the results (Figure 3 ) a definite trend in dissolved oxygen concentrations was observed for all period examined. Based on this trend dissolved oxygen concentrations are generally decreased with the increase of the distance from the upstream portion of the Evrotas main course to the downstream course of the river up to the river estuary. Evidently dissolved oxygen calculated concentrations for the main course of Evrotas for the three periods ranged between 6.9-9.3 $\mathrm{mg} \mathrm{l}^{-1}$, values which are in good agreement with field measurements for the same periods which ranged between $6.8-10 \mathrm{mg} \mathrm{l}^{-1}$.

Following the verification procedure the model was applied to predict the water quality of the several stretches of Evrotas river and its tributaries for the period of July. The results are presented in Figures 4-5. More specifically Figures 4-5 illustrates the spatial distribution of dissolved oxygen and organic carbon concentration along the main course of Evrotas river for two scenarios. Scenario-0 practically corresponds to the existing situation whereas Scenario - A corresponds to a decreased load scenario. Based on the results it is anticipated that water quality characteristics of Evrotas river and its tributaries is not satisfactory, as low dissolved oxygen concentrations were calculated for several parts of the river along with increased organic carbon concentrations. 


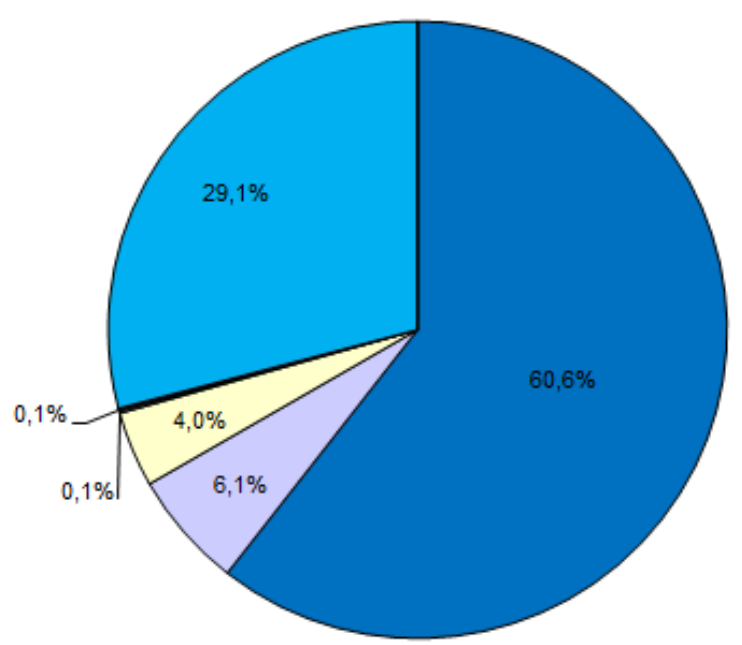

(a)
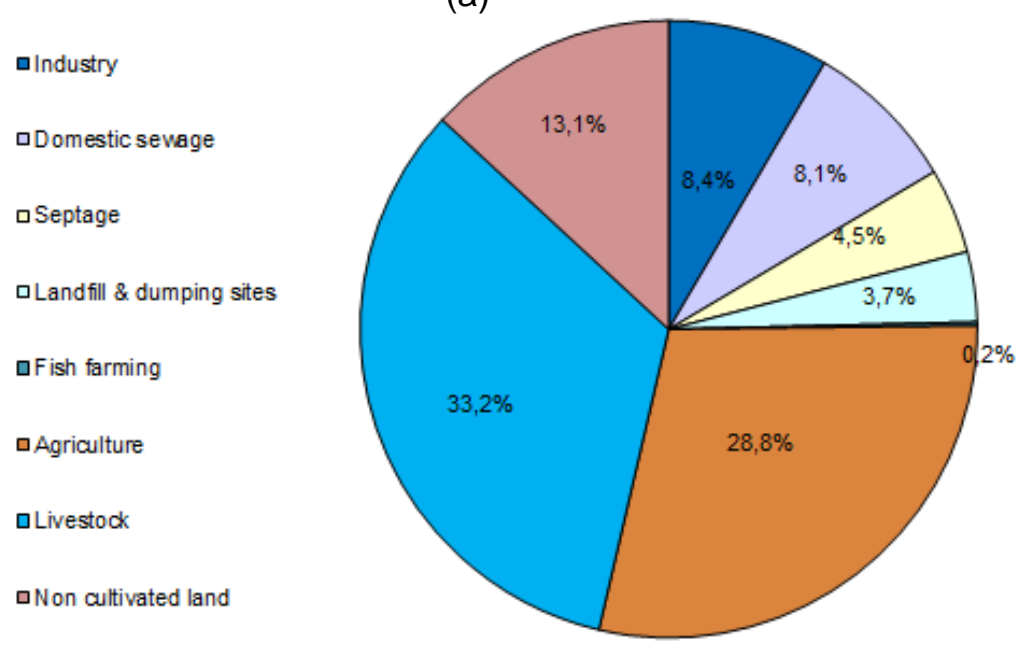

(b)

Figure 2. Distribution of (a) BOD and (b) TN annual load of point and non-point sources

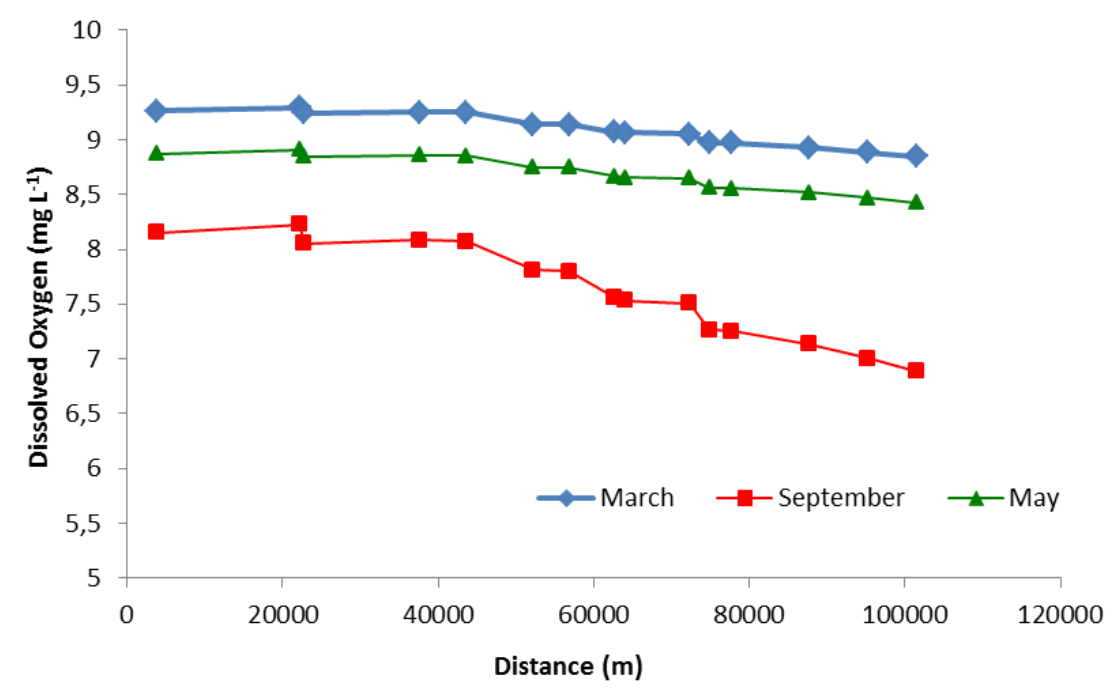

Figure 3. Dissolved oxygen concentration profile along the main route of Evrotas river for March, May and September

Evidently during the dry weather period of July and the corresponding low water flow rates, the dissolved oxygen concentrations in the last part of the main course of Evrotas river (and more 
specifically the last $13 \mathrm{~km}$ upstream the river's estuary) are below $6 \mathrm{mg} \mathrm{I}^{-1}$ (lower than $70 \%$ of saturation concentration). Accordingly BOD concentrations for the last $26 \mathrm{Km}$ upstream the river's estuary are higher than $5 \mathrm{mg} \mathrm{I}^{-1}$. By considering as limit values for the characterization of the river water quality the $6 \mathrm{mg} \mathrm{l}^{-1}$ for dissolved oxygen and $5 \mathrm{mg} \mathrm{I}^{-1}$ for BOD a first evaluation of the water quality of Evrotas RBD water bodies (with respect to its oxygenation conditions) can be performed. Figure 6 presents the results of this evaluation. As illustrated (Figure 6), 14 water bodies should be classified in the less than good quality classes due to low dissolved oxygen concentrations and/or the high organic carbon concentrations. These results are in good agreement with the suggestions made in Evrotas river basin management plan (Ministry of Environment, Energy \& Climate Change Special Secretariat for Water, 2013). More specifically among these fourteen water bodies, twelve were classified in less than good ecological status whereas for another one no classification was presented.

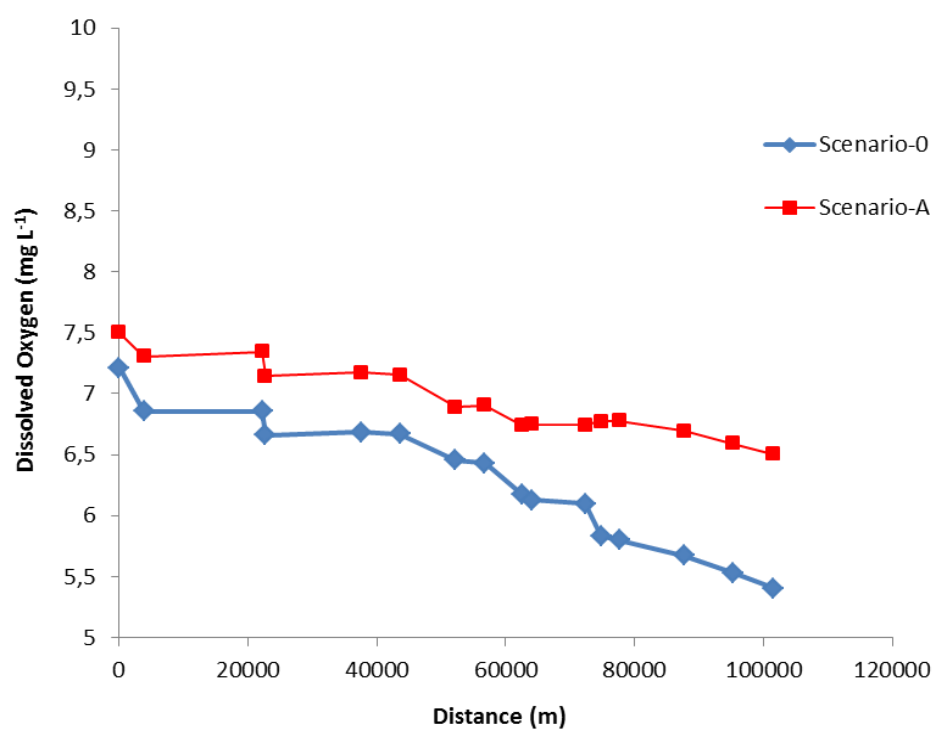

Figure 4. Dissolved oxygen concentration profile along the main route of Evrotas river for Scenario-0 (no measures) and Scenario-A (decrease of pollution loads)

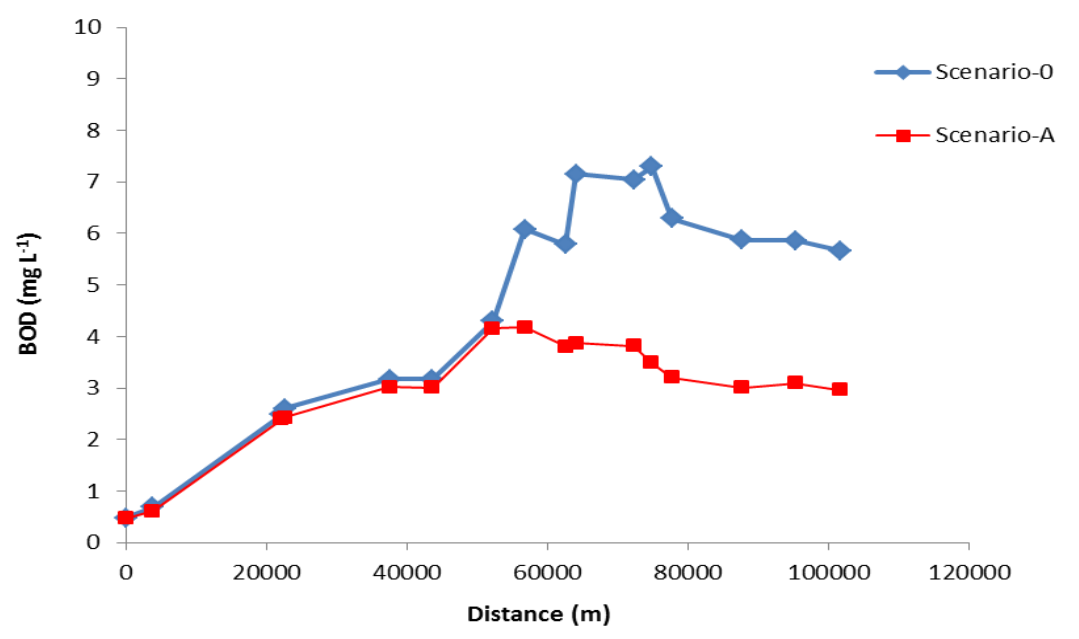

Figure 5. Organic carbon (BOD) concentration profile along the main route of Evrotas river for Scenario-0 (no measures) and Scenario-A (decrease of pollution loads)

Based on these findings the appropriate decrease in the pollution load which is required to achieve good status for all the river courses was evaluated through a series of mathematical model applications. According to the results (presented as Scenario - A) in order to achieve low organic 
carbon concentrations and satisfactory dissolved oxygen concentrations throughout the entire hydrosystem even at the dry period, an appreciable decrease to the order of $80 \%$ of the organic carbon and nitrogen load generated by the industrial units is required.

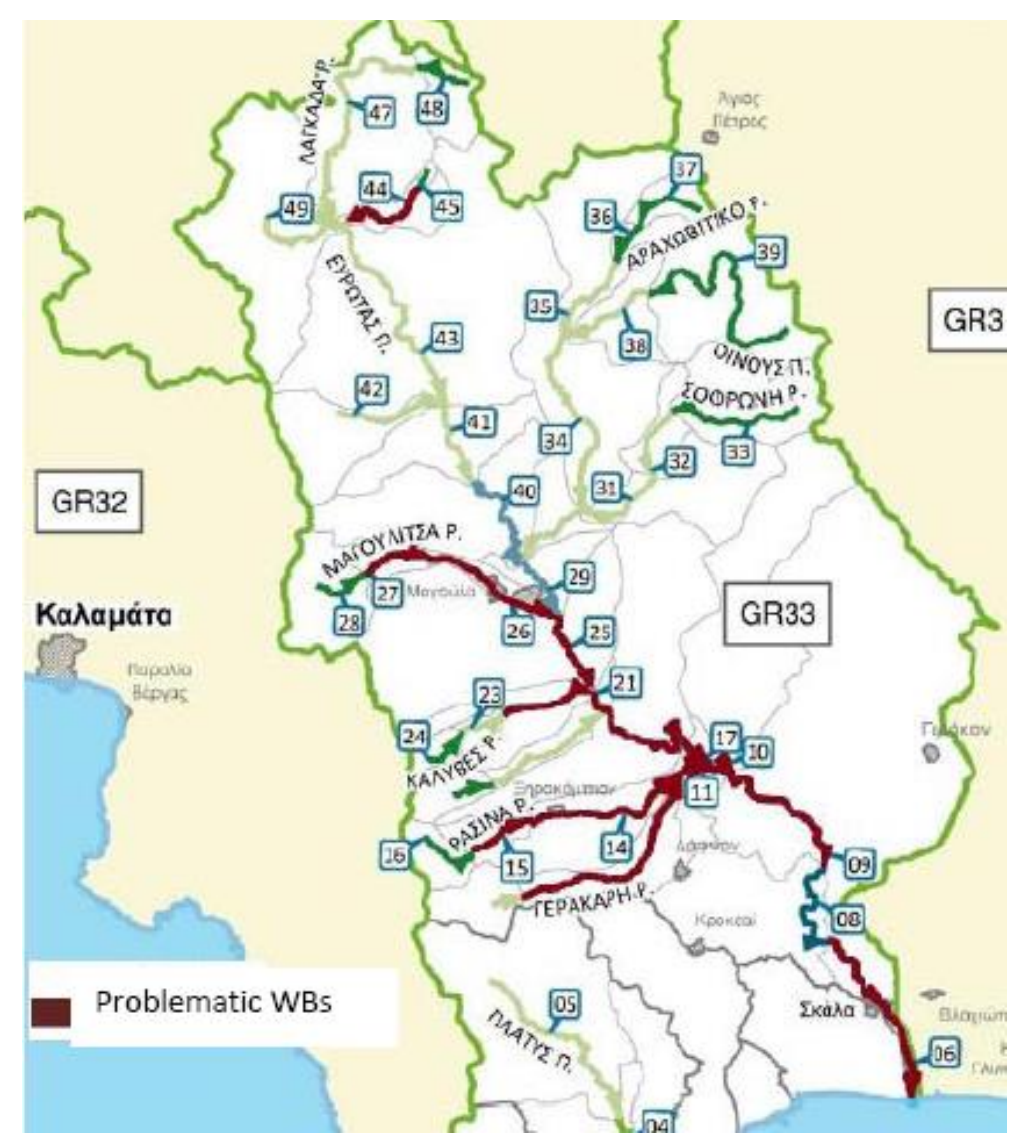

Figure 6. Characterization of the status of Evrotas RBD water bodies based on the results of the mathematical model

\subsection{Application of the extended water quality model}

As already mentioned in order to tackle the problem of uncertainty a second version of the mathematical model was developed based on the Monte Carlo simulation. Thus in order to take into consideration the random fluctuation of the constants and the model's input data, the model creates a range of possible values for each one of them and a corresponding probability distribution.
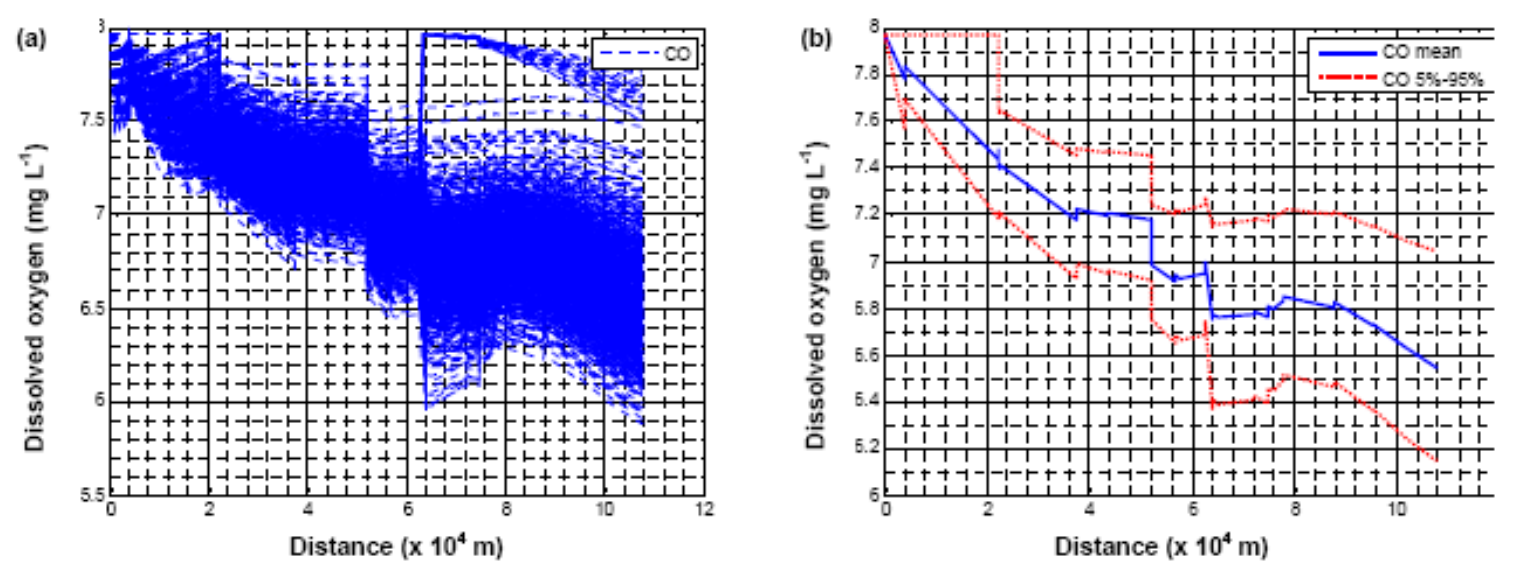

Figure 7. Results of the extended mathematical model based on Monte Carlo simulation 
Therefore the model selects, with a pseudo-random way, the value of each parameter through the specific probability distribution which can be normal, lognormal, uniform or triangular. In order to exhibit such an application a trial run was performed with the data for the period of July and by adopting a standard deviation for all kinetic constants to the order of $0.1 \mathrm{~d}^{-1}$ and $0.06 \mathrm{~m} \mathrm{~s}^{-}$for river velocity.

The results of this application are presented in Figure 7. As can be seen the model predicts the concentration of each parameter examined, not as a single value, but as a set of possible values (Figure 7a). A statistical analysis of this set of values, allows for the estimation not only of the average concentrations of the examined parameters, but also of additional statistical data like characteristic values that will not be exceeded for given confidence levels (Figure 7b).

\section{CONCLUSIONS}

A simple river water quality model was developed according to the basic principles of StreeterPhelps equations. After being validated against field measurements the model was applied for the Evrotas hydrosystem. According to the results it is anticipated that a substantial removal of organic carbon load originating from the industrial activities is needed in order to achieve high dissolved oxygen concentrations throughout the entire hydrosystem even at the dry period. Based on the present study the use of simple water quality models as evaluating tools of alternative water resources management plans was evidenced. Furthermore an extension of the simple quality model in order to provide for uncertainty assessment was also exhibited.

\section{ACKNOWLEDGMENTS}

The authors would like to acknowledge Dr. S. Michas and Mr. K. Nicolaou from Hydroexygiantiki Consulting Engineers for providing data regarding the Evrotas RBD.

\section{REFERENCES}

Ambrose R.B., Wool T.A. and Martin J.L. (1993), The water quality analysis simulation program WASP5 Version 5.10 Part A: Model Documentation, Environmental Research Laboratory, Office of Research and Development, US EPA, Athens, Georgia, USA.

Beck M.B. (1987), Uncertainty in water quality models, Water Resources Research, 23(8), 1393-1442.

Chapra S.C. and Runkel R.L. (1998), Modelling impact of storage zones on stream dissolved oxygen, ASCE Journal of Environmental Engineering, 125(5), 415-419.

DHI (2000), MIKE 11: A modelling system for rivers and channels: User guide. DHI Software.

Life Environment (2009). Environmental friendly technologies for rural development, LIFE05ENV/GR/000245, Final Report.

Parker R., Arnold J.G., Barret M., Burns L., Corruba L., Neitsch S.L., Snyder N.L. and Srinivasan R. (2009), Evaluation of three watershed-scale pesticide environmental transport and fate models, J. Am. Water Resour. As., 43(6), 1424-1443.

River basin management plan for the water district of Eastern Peloponnese (GR03), edited by Ministry of Environment, Energy and Climate Change, Special Secretariat of Water (2013).

Shanahan P., Borchardt D., Henze M., Rauch W., Reichert P., Somlybody, L. and Vanrolleghem, P. (2001), River water quality model no. 1 (RWQM1): I. Modelling approach, Water Science and Technology, 43(5), 1-9.

Thomann R.V. (1998), The future "golden age" of predictive models for surface water quality and ecosystem management, ASCE Journal of Environmental Engineering, 124(2), 94-103.

Tsakiris G. and Alexakis D. (2012), Water quality models: An overview, European Water, 37, 33-46.

Young P., Parkinson S. and Lees M. (1996), Simplicity out of complexity in environmental modelling: Occam's razor revisited, Journal of Applied Statistics, 23(2), 165-210. 